\title{
MESH Guides - Translational Research in Deaf Education Practice
}

\author{
Joy F. Rosenberg, Roger Turner, Ann Underwood, Stuart Whyte \\ University of Hertfordshire, University of Southampton
}

\begin{abstract}
Knowledge management is a growth industry though still emergent for education of the deaf. This paper investigates use of MESH (Mapping Educational Specialist knowHow) Guides to support evidence-based teaching practice. MESH Guides are 'a sustainable system using resources already available in education' (MESH, 2015). Literature review revealed a very current knowledge and research base underpins education of the deaf and is currently managed through a few main peer-review journals and websites. Focus group findings were generally positive though cautious in their view toward engaging with MESH Guides as a postgraduate learning and teaching activity. Findings from the literature revealed a significant evidence base for education of the deaf, but without yet having significant knowledge management vehicles available such as exist in other disciplines. A case study presents the development of one MESH Guide in particular (Acoustics Accessibility). A significant opportunity exists for education of the deaf as a discipline to move forward in access to evidence-based practice in the vehicle of MESH Guides.
\end{abstract}

\section{Introduction}

Nearly every sector of professional and commercial life is viewing the management of related knowledge and research as an imperative [35] Fields such as medicine have had robust systems in place since before the world wide web -- PubMed for example [37]. Other fields, such as education, are further behind. The Organisation for Economic Cooperation and Development cites the increasing attention that governments are paying to international educational comparisons. They are looking for effective social and economic policies to meet rising demands and targeting education as key. This suggests that educational practitioners should help their profession become a 'knowledge industry in the sense that its own practices are transformed by knowledge about the efficacy of those practices' [36]. Built on extensive investment of taxpayer money, strong evidence exists for teachers' desire to and difficulties in accessing research relevant to practice [23]. MESH Guides [26] and their innovators aspire to be to educational practitioners what NICE guidelines [28] in the UK or NIH Consensus Statements [27] in the USA are to clinical practitioners -- a means of translational research for the busy practitioner to help readily develop evidence-based teaching practice. They are embryonic at present; and thus there is little published on MESH Guides themselves, and none related to education of the deaf.

Healey [19] describes a nexus featuring teaching and research where subjects ideally move from passive observer to active user of research for the sake of better practice. She is touching on the rationale behind MESH Guides as does Simon Sintek [41] in his motto and book title 'Start with Why'. He proposes that this question should be the starting point of any worthwhile product or idea for robust processes and to attract significant uptake. This rationale resonates with the author's own work in training Teachers of the Deaf and Educational Audiologists for whom access to and currency of translational research is imperative. It also resonates with such access challenges in the education profession; and with MESH Guides development aim of 'supporting professional judgment with evidence from the science of learning' MESH [26]. Several entities in education of the deaf are looking to address this and these are taken up later in the literature review. Together they imply that the imperative to which Nutley [35] refers applies to any professional who wishes to 'secure the future for deaf children and young people’ [25].

This paper attempts to answer the research question: Can MESH Guide development be used to rigourously support evidence-based teaching practice in education of the deaf and teacher training? After a review of pertinent literature, methodology used to complete the review is outlined, followed by a discussion of findings, and finishing with conclusion and recommendations.

\section{Literature Review}

The key aim of this review was to investigate the merits and feasibility of use of readily accessible translational research in a time-efficient manner to promote evidence-based practice in education of the deaf. This was achieved by examining two aspects: research in the field of education of the deaf, and the broader 'knowledge management' body of research.

The first aspect revealed several categories of information management in education of the deaf; namely peer-reviewed journals, specific articles or studies, charities' and professional bodies' positions, quality standards, practice guidance and new efforts at making this information available online. Peer- 
reviewed education journals specifically for Teachers of the Deaf include many pedagogical topics, such as literacy. Watson [45] in Deafness and Education International, demonstrates that deaf children had internalised print concepts. In the Journal of Deaf Studies and Deaf Education, Apel [2] analyses spelling ability in children with hearing loss. American Annals of the Deaf produced a special issue on English reading development for individuals who are deaf and hard of hearing [44]. Luckhurst, et.al. [24] conjectures in Volta Review about lexical skills in children who use cochlear implants. Additionally, articles in journals of other disciplines or unpublished studies sometimes address practice in education of the deaf as it applies to teacher training. Swanick et al. [42] suggest a flexible framework of principles, finding it a robust model for development of critical thinking based on evidence for trainee Teachers of the Deaf. Positive Support [3] set out with one of its several aims to find the most effective strategies in education of the deaf and early intervention. Teachers of the Deaf also access the medical literature (e.g., Bond et. al. [7]) who selected from 1580 abstracts for his review on cochlear implants) and audiology research (e.g., The Nottingham Hearing Biometric Research Unit [27] whose commitment is 'to pursue research ... that can be translated into practical benefits'.

Professional bodies and charities supporting education of the deaf maintain that research is a prime concern. The British Association of Teachers of the Deaf [5] national executive committee campaign included the aim to support evidencebased and reflective practice of its membership; and the purpose of the Council on Education of the Deaf [10] includes 'reflecting current research' in its mission statement, although neither website includes a bespoke specific tool or database for doing so. The National Deaf Children's Society [30] publish position statements and quality standards on a variety of matters from inclusion to FM, all reference-based to current literature. Quality standards and practice guidance, also reference based, have been established by other bodies for areas such as early intervention [33] and paediatric tinnitus management [20] though not held centrally in one access point.

More recently new efforts to provide online resource and access to deaf-education-specific research have begun to develop. The National Sensory Impairment Partnership website [29] has had a government grant, one objective of which was to create an online resource portal for sensory impairment. A website operating in association with the Journal of Deaf Studies and Deaf Education [38] 'seeks to provide objective, evidence-based information for policy-making and practice' with ebulletins.

The second aspect of the literature review examined knowledge management and translational research more generally. The pioneering work of the medical field in the area of translational research is fairly well known. PubMed, NICE guidelines and $\mathrm{NIH}$ position statements have already been mentioned. Additional insight is available from Cochrane [11] who set a high standard. Their contributors are world leaders from 120 countries who work together to produce credible, accessible health information. Their work 'is recognised as representing an international gold standard for high quality, trusted information'.

In the education discipline, Davies [16] argues along with OECD (see introduction) that education should become more evidence-based, while distinguishing between existing research and establishing new (by virtue in part of reviewing the literature). He calls evidence-based education a set of principles for enhancing educational policy and practice. Subscribing to this argument (It would be very difficult to find arguments to the contrary.) that striving for a rationale behind practice related to evidence will produce better outcomes, then the question becomes how to go about doing so. The Association for Information Technology in Teacher Education exists in part to help answer Davies argument and the critical question that arises, with an aim to impact teacher education for effective use of digital technology providing tools and support for the dissemination of the results as key to improving educational outcomes.

There is little to no controvertible evidence against using evidence-based practice, controversies do arise, however, around the use of evidence. Cooper's article [14] explores these controversies, and examines the education profession's use of the emerging 'knowledge mobilisation' field to address research and practice and close the gap. They look at both international initiatives and discuss related challenges, the one most notable for this article's purposes being that of dissemination with rigour and accessibility. Besides controversies, concerns are identified [35] related to forming strategies to manage knowledge: types of knowledge, ways and models of use and implementation, and interventions to increase uptake. Teachers do use many if not all of these strategies as they plan interventions, curriculum or lessons, but developing the criticality to manage these well take time and thought. Another challenge to using evidence in practice is that judging the quality of knowledge (research synthesis) is complex and another reason why teachers face time constraints in terms of readily implementing research findings, as Gough [18] acknowledges. He suggests empirical study of how judgements are made, and that greater clarity will enable greater participation and implementation of research findings or impact on decision-making bodies. To help evaluate some of the debates and inform the judgements, the British Educational 
Research Association [8] describe a pyramid model of educational research with each level appealing to different audiences, and on this basis explore the research ethic of respect for persons and respect for academic integrity. This ethic underpins the framework for teaching, for evidence-based practice in education and for provision of tools to such practice to take place efficiently and effectively.

In short then, this literature review has revealed that the very current knowledge and research base underpinning education of the deaf and teacher training in this field is a highly valuable cache currently managed through a few main peer-review journals and websites. The growth industry of translational research and knowledge management is well-established in some fields and embryonic in others.

\section{Methodology}

The methods employed for this study were a literature review and focus groups.

\subsection{Literature Review}

The literature review search strategy examined three main databases (PubMed, ERIC and EBSCO) and identified 47 sources as being most relevant and fitting with the dual topics of translational research and education of the deaf. These included not only peer-reviewed journal articles and books but also in keeping with an information-age-related aim, websites that produce or disseminate some of the evidence and/or reviews. The search terms used included 'knowledge management', 'translational research', 'knowledge mobilization', 'evidencebased classroom teaching', 'research utilization', 'informed practice', 'teacher training', 'education of the deaf, hearing-impaired or hard of hearing', and 'teacher of the deaf, hearing-impaired or hard of hearing' without using abbreviations. Boolean operators were used in respect of the last two terms to broaden the search.

Quality, relevance and robustness was considered on the following bases where applicable:

- Hierarchy of evidence based on four levels of qualitative evidence [15];

- Research Excellence Framework's 4 star quality profile [39];

- $\quad$ Reporting Guidelines from EPPI (Evidence for Policy and Practice Information and Coordinating Centre) [43] .

\subsection{Focus Groups}

Additionally, focus groups were employed. Group members included stakeholders, service-users, module leaders and link tutor for master's level programmes training Teachers of the Deaf; as well as Higher Education professionals from other disciplines. Groups were convened as an assessment strategy meeting (5 participants); a course development meeting ( 8 participants); a module leaders' working party (6 participants); and a continuing professional development course small group (8 participants). Overall, the participants were mixed in terms of gender $(90 \%$ male), race $(95 \%$ white British) and adult middle age. They came from a homogenous social class, and were acquainted with one another. The recruitment source limited the nature of the data due to its inherent bias toward academics, which was viewed as beneficial to the purpose of the study. The number of groups was judged adequate for saturation (i.e., the point after which no further new insight is likely to be gained).

The chosen question paradigm was open-ended with limited structure, as this was exploratory research, in order to allow discussion to develop. They focused on

- the potential benefits and disadvantages of development of MESH Guides as a learning and teaching activity in higher education which can then be disseminated to the profession at large, and

- the benefits of and barriers to integration of research to education practice.

Data/discussions of the focus groups were recorded in written notes. Consensus confirmed verbally and also recorded. Classical content analysis was applied, adapted to allow placing chunks of data into themed similar groupings.

\section{Results and Discussion}

\subsection{Focus Groups}

Focus group consensus revealed a generally positive view of MESH Guide use as a learning and teaching activity for Teachers of the Deaf as follows: It lends itself readily to the type of critical thinking necessary in postgraduate work, and contributes to the development of the profession. The need for literature review as part of the work, and the critical judgement that could be evidenced in the production were deemed merit-worthy aspects. It promotes collaborative thinking and working across the profession, and could be valuable for inset training. Concerns enumerated related to intellectual property in light of the creative commons attribution noncommercial international license; to keeping data and implications current, to quality assurance of the editorial board, to cost implications for authors and institutions and to impact on recruitment and enrolment for fee bearing courses. As mentioned in the literature review, there is a paucity of studies about MESH Guides, so focus group participants did 
not have references upon which to rely but instead used their experience to infer positive expectations and concerns. Personal integrity, the development of new knowledge, public safety, quality assurance and a competitive current edge were all cited as reasons for educators to base their practice on sound research. Certain complexities proved obstructive to utilizing research regularly in the classroom, including disinterest, time constraints, complex terminology, workload and priorities clashes [4].

\subsection{Literature Review}

Literature Review results revealed that a significant valuable evidence base exists in various forms and from various sources for education of the deaf, that successful models exist for translational research such as NICE guidelines, and that knowledge management is a growth industry in which the embryonic MESH Guide development sits.

MESH Guides aim to help provide some of the clarity to which Gough [18] refers, by virtue of the structures and the editorial boards. Nutley's [35] concerns for managing knowledge are factors considered in MESH Guides concept map development within which editors work with authors to take a well-researched text document and to an editorial board where after approval it is published online in an easily navigable layout and slated for regular updates. Comparatively, the strength of clinical guidelines to influence practice [46] is rooted in the desire to resolve challenges that healthcare systems face such as costs, demand, expensive technologies, variations in service delivery and the very human desire of healthcare professionals to provide the best care possible. Very similar factors impact education of the deaf, and teachers partnering with parents also have an intrinsic aim of doing what is best for children who are deaf. For these children the advent of new technologies in early identification and intervention have heralded a paradigm shift and the potential for much better outcomes and quality of life. Still, professionals would be better able to empower children and families to realise that potential, if they had more pragmatic access in a timely way to translational research.

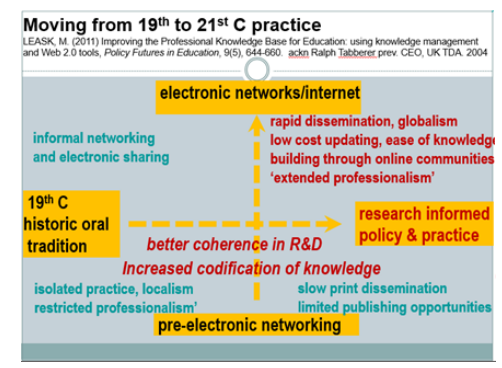

Figure 1. Knowledge Management paradigm shift
Capel, et.al. [9] outline forms of professional knowledge to include content, curriculum, general pedagogy, educational contexts and ends, learner characteristics, and finally pedagogical content knowledge (i.e. 'how to teach specific concepts effectively so all learners can progress'). It is this last form especially that stands to benefit most from the advent of a tool like MESH Guides. The advent of this tool is fitting to the age that Tabberer in Leask [21] modelled, illustrating a paradigm shift from $19^{\text {th }}$ to $21^{\text {st }}$ century information development and exchange as seen in Figure 1, used with permission from Leask [22].

Roger's theory of Diffusions of Innovations [40] seeks to explain the spread through societies of new ideas and technologies by looking at how and why. He used a bell curve to illustrate, it with innovators being the first $2.5 \%$ of take-up, as seen in Figure 2, used with permission from Leask [21]. Although MESH Guides are very much in the innovators stage, nevertheless a start has been made on which all future developments can now build.

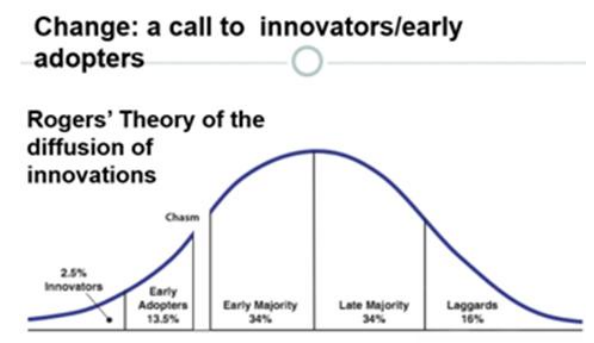

Figure 2. Roger's Theory of the Diffusion of Innovations

Considerations for future work in this area include establishing new focus groups as well as working parties for specific tasks. These could be related to using MESH Guide development as an actual learning and teaching activity for training Teachers of the Deaf and for classrooms with deaf children. Data that could be considered in future can be collected from MESH Guides themselves, as the databases can be interrogated for different purposes relating to such parameters as the number of users over a given period of time, the countries from which they come, the feedback provided in open-ended surveys, and impact ratings.

\section{Case Study: Acoustic Accessibility MESHGuide}

\subsection{Introduction and Background to Case Study}

To borrow nomenclature from the medical field, the aetiology and anatomy of a specific MESHGuide - Acoustic Accessibility [26] - is considered here. 
This is in order to provide demonstrable outcomes of the efforts to date of one of the newer MESH Subject and Strand editorial boards, 'Deafness and Hearing Impairment'. The editorial board is comprised of men and women in mid-to-late career, and includes Teachers of the Deaf, Educational Audiologists and School-based action researchers, all of whom serve also as BATOD Foundation Trustees. It brings together a wide range of specialist knowledge and skills in different areas targeting at improving the teaching and learning of deaf children including initial teacher training, experiential education, research skills and ongoing accessible continuing professional developing especially for teachers working in isolated areas or with no funding options.

Data collected for the writing of this section include interviews, workshop presentations, minutes of online meetings, and correspondence.

Just as MESHGuides are in the embryonic stage, so too were the aims of educators and audiologists interested in gathering research data related to acoustics. This effort endeavoured to answer the question of why creating a good listening environment is important. It started initially with two study days which produced an annotated bibliography hosted on the BATOD Foundation website. The Foundation was tasked with being a catalyst organization - securing excellent learning outcomes for deaf children by gathering information relevant to deaf education and making it readily signposted and accessible.

Due to the limitations of the study day method in terms of access to a broader audience due to funding, timing, staffing and logistics; the notion moved to developing a MESHGuide. The added advantage of MESHGuides extends the range of impact from local to worldwide. This provides the teaching profession (both special needs and mainstream) with accessible evidence-based research information on best practice in the area of acoustics accessibility and its relationship to teaching and learning.

\subsection{Initial development}

The editorial board attended a productive workshop, the purpose of which was to learn about the principles and techniques of creating MESHGuides. The structure of the day allowed participants to contribute to the areas each thought was most important to explore. It included a background tutorial and ended with a very clear outline of an Acoustics and Accessibility MESHGuide with an agenda for production revision and launch in the coming months.

The highly stimulating background tutorial provided history of knowledge management related to education and included challenges to accessing research to inform policy and practice. It covered translational research processes, limitations and solutions of systematic reviews, overview of the knowledge base underpinning educational practice; and the theory and practice related to knowledge mobilisation globally.

With the goal of having a publishable provisional summary by the end of the day, the second half of the day was given to group work on individual MESHGuide summaries with opportunities to contribute individual ideas and receive formative feedback. The style aim was for a professional tone which enables educators to test out the MESHGuide's advice, as opposed to a more formal academic tone. Crucially, agreement first had to be reached on the starting point, what the authors want readers to know about our area of knowledge, with the answer to that question forming the structure of the MESHGuide. Using a mind-map brainstorming technique, this structure was fleshed out, ultimately transferring the actual text into a document that the web-builder will use to build the MESHGuide online.

Collaborative tools such as online shared documents that all group members could access to update or change, allowed a single document to be a receptacle for ideas and developing text. Multiple users could amend it in real time and avoid the confusion of multiple documents and versions.

A table template was provided which later became the functional tiles in the actual online MESHGuide (Figure 3). (End users of the MESHGuides online can also generate a printable PDF of MESHGuide material.) Participants attempted to expand each cell with relevant information or identify what was needed to either be collated or created.

Team members were advised to have the top ideas/issues/solutions in mind and to bring resources from which to develop the MESHGuide including reports, knowledge of specific effective practices, research evidence and bibliographies. All four of the board members are specialists in different areas targeted at improving the teaching and learning of deaf children with knowledge of specific effective practice. For example, one such item was a report on an investigation into the validity and reliability of key findings about trends in the impact on teaching and learning of audio distribution (soundfield) systems, to help inform discussions as the MESHGuide was developed.

\subsection{Anatomy of the MESHGuide}

The MESHGuide online manifests as a single table format with five columns of boxes with content of each box in a single cell. Although not rigid, this format works well on most web browsers and screens. Clearly marked headings, hyperlinks, images and further content are revealed when the box is clicked.

After a main title and summary/abstract, the 
recommended format, each forming a column of tiles, was:

- Column 1: Evidence: References or weblinks in internationally accepted format.

- Column 2: Definitions and Background: How to diagnose the learning problem or how the issues present in the classrooms in the study.

- Column 3: Contextual matters which demonstrate how research plays out in practice.

- Column 4: Pedagogical interventions or further resources.

- Column 5: Case studies or examples where these exist.

\section{MESHGuides}

\section{Acoustics - listening and learning}

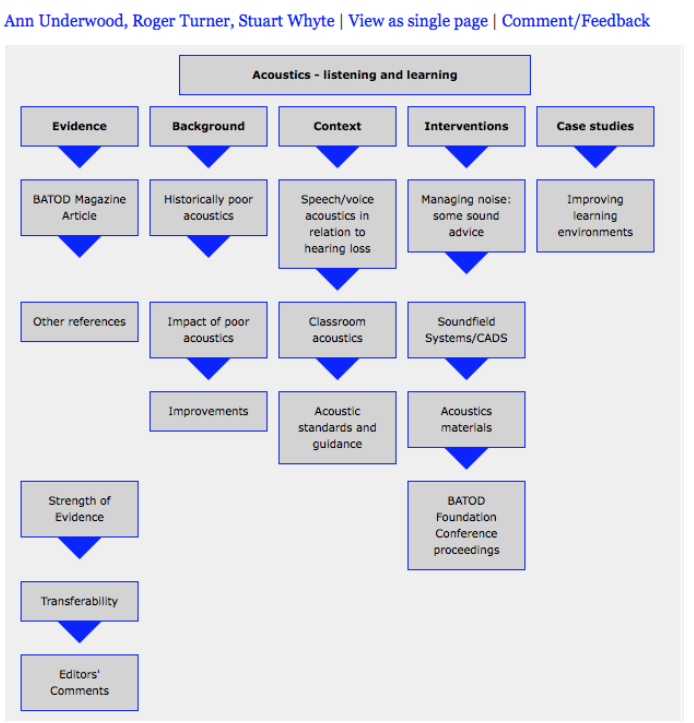

Figure 3. Acoustic Accessibility MESH Guide

\subsection{Revision}

The Acoustic Accessibility MESHGuide was developed over a period of seven months by four subject specialists as a volunteer effort aided by two technical/structural advisors. The work was accomplished remotely using a variety of online writing and communication tools. Revisionary decisions, both major and minor, had to be made along the way using essential colour coding for clarity. Tags and links were added including links to national bodies, and text expanded and edited. References and citations were cross-checked, updated and merged. Considerations were given to filling gaps and wording was strengthened, clarified and made more succinct. Sections were moved about and segues added to clarify structures. Pros and cons of technical decisions were made such as whether to upload documents or link to sources.
Case Studies were added as they became available, and the invitation made for future additions from users. Layout was fine-tuned Meeting minutes noted that the MESHGuide improved with every edit and became a foundation upon which future MESHGuides could be based. Indeed it is now used as a standard for layout and quality for other new MESHGuides for more consistency across the website. Final decisions before launch were made regarding under which category the MESHGuide should appear (General Pedagogy linked to Special Needs). After the launch, this MESHGuide along with others remains an organic process as editing and growth can be on going, and indeed is required for quality assurance.

\subsection{Evaluation of the process and future steps}

After the text-based version of the MESHGuide is created, revised and agreed, eventually it can be submitted to the relevant subject or strand editorial board ready for a peer-review and recommendations on drafts before the final MESHGuide is processed and uploaded onto the website. Suggested updates will normally be decided by authors and the relevant editorial board. Authors are asked to review their MESHGuide on a regular basis.

Analytic data about each MESHGuide can be interrogated from the site, counting hits and page views and in due course this can be accessed for a view to how the MESHGuide is being used. Quality is inherent in the time-frames for shelf life and future revisions, with right of first refusal belonging to initial authors per the creative commons attribution non-commercial license. The authors agree to continually develop and improve the content of MESHGuides and actively welcome comment from all readers on how improvements might be achieved.

As with any online resource, software glitches, programming errors and even malicious code are difficulties which might be encountered. MESHGuides are hosted by a major web hosting company uses two servers, one holding the main overall site and the second which holds the MESHGuides.

Next topics being considered by the editorial board on deafness and hearing impairment are likely to be in the area of autism and deafness; tablets and apps, literacy. Higher education teacher training skills would be invaluable in helping decide the shape and content of our possible MESHGuides. In order to proceed to deliver the service the profession needs, the team must grow in number and are busily recruiting new authorship and participation that would greatly enhance the opportunity for discussion and production. The current base is enthusiastic, experienced and skilled, 
but small. Having successfully launched one MESHGuide, they hope to encourage current practitioners to look at and apply best practice and then report back on their own research findings so giving an on-going life to this MESHGuide and any future one. Further training/study days, marketing, funding-raising, publicity at conferences, as exhibitors and presenters, and in professional magazines are necessary steps in developing future MESHGuides. With authors from a very large and growing number of countries now involved in creating and using MESHGuides which are available online constantly, this editorial board's view is that it promises to be an easily accessible route to sharing research information to impact professional practice globally.

\section{Conclusion}

'The last decade of education change has been characterised by the rise of evidence-based policy and practice agendas. Internationally, we are witnessing efforts to increase and incorporate research use in public services' [14]. Now more than ever before with a constantly growing body of evidence and knowledge being published at an accelerating rate, Teachers of the Deaf have the opportunity to make an even more significant difference in the lives and outcomes of children and young people who are deaf, if they can access the evidence in a timely way for regular use as a basis for their teaching. Current knowledge and research underpinning education of the deaf is highly valuable and currently managed mainly through a few main peer-review journals and websites. A step further for these valuable contributions collectively would be to engage with the particularly pragmatic aim of MESH Guides which is to make the implications of the evidence for education practice very readily available globally to classroom practitioners who have significant time constraints. Limitations of this study as well as of MESH Guides themselves is essentially that not enough longitudinal data yet exists to draw authoritative conclusions without some amount of speculation. Nevertheless, sufficient potential exists so that BATOD Foundation Trustees [6] have formed a subject editorial board within MESH Guides on Deafness and Hearing Impairment with the stated aim of providing easily accessible and robust information for creating good listening and learning environments.

The growth industry of translational research and knowledge management is well-established in certain disciplines and just emergent in others such as education. MESH Guides, in its embryonic stage, stand at the juncture between these two as an opportunity and vehicle to move the wealth of the existing and growing underpinning research for education of the deaf, very actively and pragmatically into the minds and hands of those who are at the chalk face. Adapting a line from the medical field [11] 'MESH Guides exists so that education decisions get better'.

\section{References}

[1] Association for Information Technology in Teacher Education. (2015, Feb 10). Retrieved from Association for Information Technology in Teacher Education: http://www.itte.org.uk/

[2] Apel, K., \& Masterson, J. (2009). Comparing the Spelling and Reading Abilities of Students With Cochlear Implants and Students With Typical Hearing. Journal of Deaf Studies and Deaf Education.

[3] Bamford, J., Carr, G., Davis, A., Gason-Ramos, M., Lea, R., McCracken, W., \& Young, A. (2009). Positive Support in the lives of deaf children and their families. Unpublished Article - University of Manchester, University College Londond.

[4] Barefoot, H. (2015). Barriers to research integration in teaching, class discussion. Linking Theory to Practice CPAD module, (p. 2). Hatfield.

[5] BATOD. (2015, Jan 30). Retrieved from British Association of Teachers of the Deaf: http://www.batod.org.uk/index.php?id=/batod/aboutbatod /nec/elections/2013-2015/candidates13.htm

[6] BATOD Foundation. (2015, Feb 22). Retrieved from BATOD Foundation:http://www.batodfoundation.org.uk/ index.php?p=1_3_About

[7] Bond, M., Elston, J., Mealing, S., Anderson, R., Weiner, G., Taylor, Z., \& Stein, K. (2009). Systematic reviews of the effectiveness and cost-effectiveness of multi-channel unilateral cochlear implants for adults. Clinical Otolaryngology, 199-211.

[8] Brown, M., Edwards, A., Evans, M., Pring, R., Scott, S., Westcott, M., \& Bassey, M. (2015, Jan 25). Good Practice in Educational Research Writing (2000). Retrieved from BERA British Educaitonal Research Association: https://www.bera.ac.uk/researchersresources/publications/good-practice-in-educationalresearch-writing-2000.

[9] Capel, S., Leask, M. T., \& Eds. (2013). Learning to teach in the secondary school: A companion to school experience 6th edition. Routledge.

[10] CED. (2015, Feb 20). Retrieved from Council on Education of the Deaf:http://councilondeafed.org/ mission/.

[11] Cochrane. (2015, Feb 4). Retrieved 4 Feb 2015 from Cochrane Review: http://www.cochrane.org/.

[12] Comparing the Spelling and Reading Abilities of Students With Cochlear Implants and Students With 
Typical Hearing. (2014). Journal of Deaf Studies and Deaf Education.

[13] CONSORT Guidelines 2010. (2015, Feb 7). Retrieved from CONsolidated Standards of Reporting Trials: http://www.consort-statement.org/consort-2010

[14] Cooper, A., Levin, B., \& Campbell, C. (2009). The growing (but still limited) importance of evidence in education policy and practice". Journal of Educational Change, 10(1), 159-171.

[15] Daly, J., Willis, K., \& Small , R. (2009). A hierarchy of evidence for assessing qualitative health research. Journal of CLinical Epidemiology, 43-49.

[16] Davies, P. (1999). What is Evidence-Based Education. British Journal of Educational Studies, 47(2), 108-121.

[17] Ferguson, M., \& Henshaw, H. (2014). Assessing quality of research articles. British Academy of Audiology. Bournemouth.

[18] Gough, D. (2007). Weight of evidence: a framework for the appraisal of the quality and relevance of evidence. Research Papers in Education, 213-228.

[19] Healey, M. (2005). Linking research and teaching: disciplinary spaces. In B. (ed.), Reshaping the university: new relationships between research. Maindenhead: McGraw-Hill/Open University Press.

[20] Kentish, R., Kennedy, V., Benton, C., Rogers, C., Rosenberg, J., Munro, C., \& Adams, J. (2015, March). Practice Guidance: Tinnitus in Children and Teenagers. BSA Practice Guidance. British Society of Audiology.

[21] Leask, M. (2011). Improving the Professional Knowledge Base for Education: using knowledge management and Web 2.0 tools. Policy Futures in Education, 9(5), 644-660.

[22] Leask, M. (2015a). Translational research workshop: writing a MESHGuide. MESH TrainingWorkshop, (p. 25). Bedford.

[23] Leask, M. (2015b, Feb 28). Draft questions/concerns [by email].

[24] Luckhurst, J., Lauback, C., \& VanSkiver, A. (2013). Differences in Spoken Lexical Skills: Preschool Children with Cochlear Implants and Children with Typical Hearing. Volta Review.

[25] Mary Hare. (2015, Feb 24). Retrieved Feb 24, 2015, from Mary Hare: www.maryhare.org.uk

[26] MESH. (2015, Sep 29). Retrieved from Mapping Education Specialist KnowHow: www.MESHguides.org

[27] National Insitutes of Health. (2015, Feb 11). Retrieved from National Insitutes of Health: http://nih.gov/

[28] National Institute for Health and Care Excellence.
(2015, Feb 1). Retrieved from National Institute for Health and Care Excellence: http://www.nice.org.uk/

[29] National Sensory Impairment Partnership. (2015, Feb 1). Retrieved from National Sensory Impairment Partnership: https://www.natsip.org.uk/index.php/ workstreams-and-groups.

[30] NDCS. (2015, Jan 18). Retrieved from National Deaf Children's Society:http://www.ndcs.org.uk/about us/position_statements/index.html

[31] Newman, M., \& Elbourne, D. (2005). Improving the usability of educational research: guidelines for the REPOrting of primary empirical research Studies in Education (the REPOSE guidelines). Evaluation and Research in Education, 18(4), 201-212.

[32] NHS Evidence. (2015, Feb 13). Retrieved from NHS Evidcence:

http://www.evidence.nhs.uk/Search?q=cochlear+implant

[33] NHSP. (2015, Feb 4). Retrieved from Newborn Hearing Screening Programme:http://hearing.screening. nhs.uk/standardsandprotocols

[34] NIH. (2015, Jan 31). Retrieved from National Institute of Health Research:http://www.hearing.nihr. ac.uk/about-us

[35] Nutley, S., Walter, I., \& Davies, H. (2003). From Knowing to Doing. Evaluation, 9 (2), 125-148.

[36] OECD. (2014). Education-at-a-Glance-2014. Retrieved from Organization for Economic and $\mathrm{Co}$ Operative Development: www.oecd.org/edu/Educationat-a-Glance-2014.pdf

[37] PubMed. (2015, Feb 10). Retrieved from National LIbrary of Medicine, National Institutes of Health: http://www.ncbi.nlm.nih.gov/pubmed

[38] Raising and Educating Deaf Children. (2015, Feb 1). Retrieved from Raising and Educating Deaf Children: $\mathrm{http}: / /$ raisingandeducatingdeafchildren.org/

[39] REF. (2015, Feb 20). Retrieved from Research Excellence Framework: http://www.ref.ac.uk/panels/ assessmentcriteriaandleveldefinitions/.

[40] Rogers, E. (2003). Diffusion of Innovations, $5^{\text {th }}$ Edition. Simon and Schuster.

[41] Sintek, S. (2011). Start with Why. Penguin.

[42] Swanick, R., Jarvis, J., Kitchen, R., McCracken, W., O;Neil, R., \& Power, S. (2014). Following Alice: theories of critical thinking and reflective practice in action at postgraduate level. Teaching in Higher Education, 19(2), 156-169.

[43] UCL, E., (2015, Feb 15). Guidelines for the REPOrting of primary empirical research Studies in Education (The REPOSE Guidelines). Retrieved from EPPI Evidence for Policy and Practice Information and Co-ordinating Centre:http://eppi.ioe.ac.uk/cms/Default. 
aspx?tabid=759

[44] Wang, Y., \& Andrews, J. (2014). Reading and Deaf Individuals: Perspectives on the Qualitative Similarity Hypothesis. American Annals of the Deaf, 319-323.

[45] Watson, L. (2009). Early print concepts: insights from work with young deaf children. Deafness and Education International.

[46] Woolf, S. (1999). Potential benefits, limitations, and harms of clinical guidelines. British Medical Journal, Potential benefits, limitations, and harms of clinical guidelines. 